\title{
MODELLING AND CONTROL OF HOT-AIR SYSTEM UNDER CONDITIONS OF UNCERTAINTY
}

\author{
Radek Matušů and Roman Prokop \\ Department of Automation and Control Engineering \\ Faculty of Applied Informatics \\ Tomas Bata University in Zlín \\ Nad Stráněmi 4511, 76005 Zlín, Czech Republic \\ E-mail: \{rmatusu; prokop\}@fai.utb.cz
}

\section{KEYWORDS}

Hot-Air System, Parametric Uncertainty, Algebraic Synthesis.

\begin{abstract}
The contribution deals with modelling and control of temperature in laboratory model of hot-air system under conditions of parametric uncertainty. In the first instance, the first and second order parametrically uncertain mathematical models of the plant are constructed, and then they are utilized for design of various controllers with conventional structure. The control synthesis exploits general solutions of Diophantine equations in the ring of proper and stable rational functions. Robust stability of final closed control loops is tested using the value set concept and zero exclusion condition.
\end{abstract}

\section{INTRODUCTION}

The uncertainty represents serious problem in many real control applications. One of convenient approaches to uncertain modelling and description supposes no variations in the structure but only in parameters of the controlled system. In such case, one speaks about parametric uncertainty. In spite of the uncertain conditions, the often requirement consists in application of a cheap controller with simple PI or PID structure and fixed coefficients which would ensure stability and desired control behaviour for all expected values of the uncertain parameters.

A potential solution of this task consists in the usage of continuous-time controllers designed through general solutions of Diophantine equations in the ring of proper and stable rational functions $\left(\mathrm{R}_{\mathrm{PS}}\right)$, Youla-Kučera parameterization and divisibility conditions. The principal idea of this approach is adopted from (Vidyasagar 1985; Kučera 1993) while the control design itself is proposed and analysed e.g. in (Prokop and Corriou 1997; Prokop et al. 2002; Matušù et al. 2008). This method brings a single tuning parameter $m>0$ which can be used for influencing the control response. Later on, closed-loop robust stability can be verified for example with the assistance of the value set concept and zero exclusion condition (Barmish 1994; Bhattacharyya et al. 1995).
This paper aims to present a simple way of constructing a model with parametric uncertainty and also an algebraic approach to continous-time robust control design. The proposed techniques are applied during control of bulb temperature in laboratory model of hotair tunnel. In a set of experiments, the controlled system is approximated by first or second order transfer functions with parametric uncertainty, the controllers are designed, the robust stability is verified, and the final control responses are tested and evaluated.

\section{HOT-AIR PLANT DESCRIPTION}

The controlled plant has been represented by laboratory model of hot-air tunnel constructed in VŠB - TU of Ostrava (Smutný et al. 2002). Generally, this object can be seen as multi-input multi-output (MIMO) system, however, the experiments have been done on a selected single-input single-output (SISO) loop. The model is composed of the bulb, primary and secondary ventilator and an array of sensors covered by tunnel. The bulb is powered by controllable source of voltage and serves as the source of light and heat energy while the purpose of ventilators is to ensure the flow of air inside the tunnel. All components are connected to the electronic circuits which adjust signals into the voltage levels suitable for CTRL 51 unit. Finally, this control unit is connected with the PC via serial link RS232. The diagram of the plant and the whole control system is shown in fig. 1 .

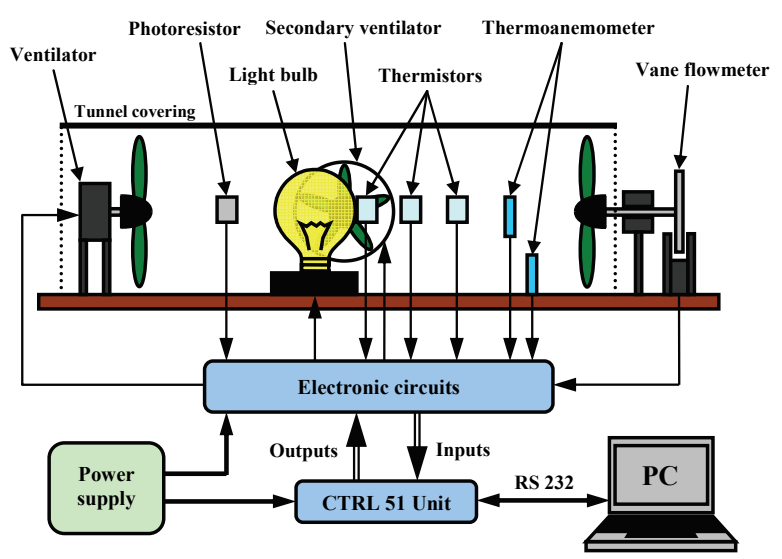

Figure 1: Scheme of Hot-Air Tunnel and Control System 
The CTRL 51 unit has been produced in the Academy of Sciences of the Czech Republic (Klán et al. 2003). The tables 1 and 2 denote the meaning of input and output channels of this unit, respectively.

Table 1: Connection of Input Signals of CTRL 51 Unit

\begin{tabular}{|c|c|}
\hline Input channel & Sensor \\
\hline Input $1(y 1)$ & $\begin{array}{l}\text { Light intensity of the } \\
\text { bulb (photoresistor) }\end{array}$ \\
\hline Input $2(y 2)$ & $\begin{array}{c}\text { Temperature a few mm } \\
\text { from the bulb ( } 2 \mathrm{nd} \\
\text { thermistor) }\end{array}$ \\
\hline Input $3(y 3)$ & $\begin{array}{l}\text { Temperature of the bulb } \\
\text { (1st thermistor) }\end{array}$ \\
\hline Input $4(y 4)$ & $\begin{array}{c}\text { Temperature at the end } \\
\text { of the tunnel (3rd } \\
\text { thermistor) }\end{array}$ \\
\hline Input $6(y 6)$ & $\begin{array}{c}\text { Airflow speed } \\
\text { (thermoanemometer) }\end{array}$ \\
\hline Input $7(y 7)$ & $\begin{array}{l}\text { Airflow speed (vane } \\
\text { flowmeter) }\end{array}$ \\
\hline
\end{tabular}

Table 2: Connection of Output Signals of CTRL 51 Unit

\begin{tabular}{|c|c|}
\hline Output channel & Actuator \\
\hline Output 1 $(u 1)$ & $\begin{array}{c}\text { Bulb voltage (control of } \\
\text { light intensity and bulb } \\
\text { temperature) }\end{array}$ \\
\hline Output 2(u2) & $\begin{array}{c}\text { Voltage of the primary } \\
\text { ventilator (control of } \\
\text { revolutions) }\end{array}$ \\
\hline Output $3(u 3)$ & $\begin{array}{c}\text { Voltage of the secondary } \\
\text { ventilator (control of } \\
\text { revolutions) }\end{array}$ \\
\hline
\end{tabular}

All presented identification and control experiments were performed in MATLAB 6.5.1 environment. The communication between MATLAB and CTRL 51 unit was arranged through four user functions (for initialization, reading and writing of data and for closing) and the synchronization of the program with real time was done via "semaphore“ principle (forthermore, the utilization of MATLAB functions „tic“ and „toc“ as an alternative were tested). To ensure the sufficient emulation of the continuous-time control algorithms, the sampling time $0.1 \mathrm{~s}$ was used. The detailed information about utilization of serial link under MATLAB including mentioned user routines, program synchronization mechanism and several tests can be found in (Dušek and Honc 2002). The discretization of control laws was carried out by left rectangle approximation method.

The considered loop covers bulb voltage $u 1$ (control signal), which influences temperature of the bulb y3 (controlled variable). The other actuating signals were preseted to constant values - primary ventilator voltage $u 2$ to $2 \mathrm{~V}$ and secondary one $\mathrm{u} 3$ to $0 \mathrm{~V}$.

\section{IDENTIFICATION OF THE SYSTEM}

Naturally, the first task was to determine static and dynamic behaviour of the system. The trio of static characteristics measured during 3 different days is plotted in fig. 2 .

Note, that the system properties markedly depend on current conditions and that it can be saturated in higher levels of $u 1$. Therefore, the value $10 \mathrm{~V}$ was excluded from the subsequent process of identification. The fig. 3 shows the set of step responses with the starting point $u 1=0 \mathrm{~V}$ while the final value of $u 1$ is from 1 to $9 \mathrm{~V}$ and the fig. 4 depicts the similar responses from $u 1=5 \mathrm{~V}$ to $6,7,8$ and $9 \mathrm{~V}$.

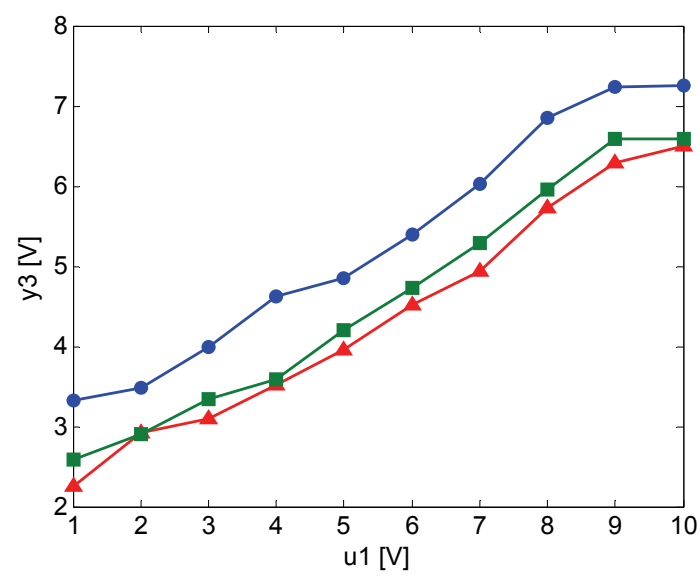

Figure 2: Static Characteristics of the System

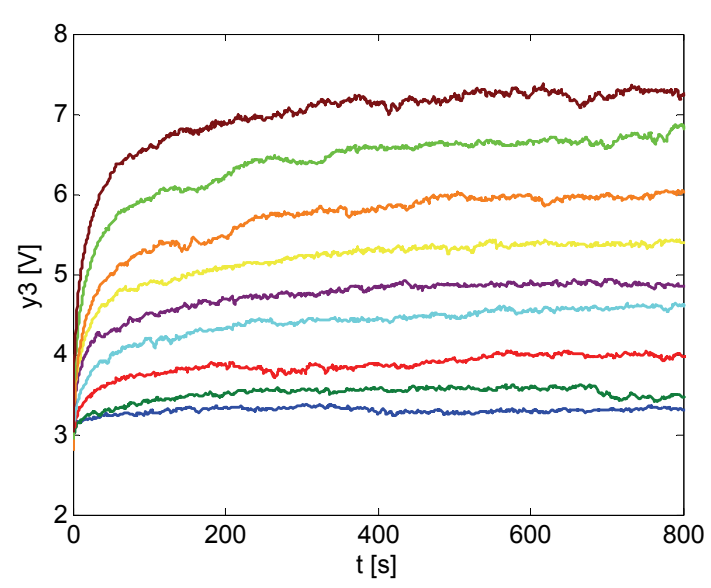

Figure 3: Step Responses Starting from $u 1=0 \mathrm{~V}$ 


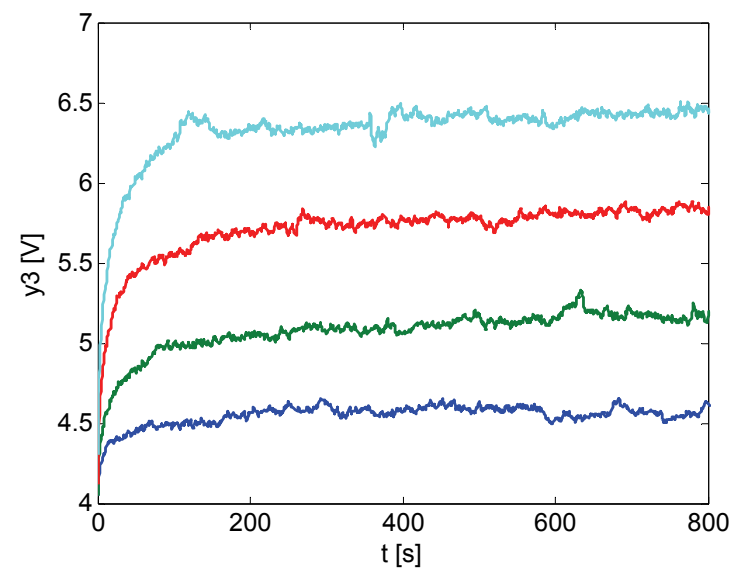

Figure 4: Step Responses Starting from $u 1=5 \mathrm{~V}$

All measured responses were normalized and approximated by step response of system with selected structure. In the first instance, it has been approximated by first order system:

$$
G(s)=\frac{K}{T s+1}
$$

However, with respect to the character of dynamics which is initially very fast and gradually starts to slow, the first order plant represents simplified solution. On that account, also the second order system:

$$
G(s)=\frac{K(\tau s+1)}{\left(T_{1} s+1\right)\left(T_{2} s+1\right)}
$$

has been assumed. The least squares method was used for identification of time constants. The example of approximation by first (1) and second order system (2) is given in fig. 5 . It belongs to $u 1$ step-change from 0 to $6 \mathrm{~V}$. In this particular case, the transfer functions are:

$$
\begin{gathered}
G(s)=\frac{0.4107}{37.2289 s+1} \\
G(s)=\frac{0.4107(119.7679 s+1)}{(9.5334 s+1)(186.3907 s+1)}
\end{gathered}
$$

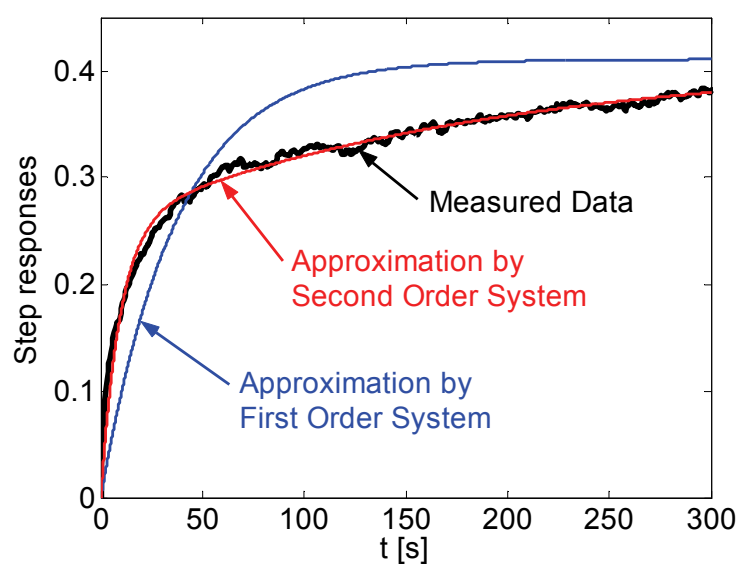

Figure 5: Example of Approximations
In an effort to stress more the initial part of responses with fast dynamics, only first $100 \mathrm{~s}$ have been included in optimization of $T$ for first order. The complete results both for first and second order are shown in table 3 .

Table 3: Identification Results

\begin{tabular}{|c|c|c|c|c|c|}
\hline$u 1[\mathrm{~V}]$ & $K[-]$ & $T[\mathrm{~s}]$ & $\tau[\mathrm{s}]$ & $T_{1}[\mathrm{~s}]$ & $T_{2}[\mathrm{~s}]$ \\
\hline $0-1$ & 0.2435 & 41.2259 & 27.1160 & 3.6437 & 72.1970 \\
\hline $0-2$ & 0.2833 & 47.2704 & 33.6512 & 3.2631 & 92.8624 \\
\hline $0-3$ & 0.3594 & 43.3580 & 115.9249 & 11.9881 & 186.0546 \\
\hline $0-4$ & 0.4274 & 48.2019 & 109.6962 & 10.8675 & 195.5283 \\
\hline $0-5$ & 0.3740 & 37.2064 & 76.1006 & 6.6347 & 130.6889 \\
\hline $0-6$ & 0.4107 & 37.2289 & 119.7679 & 9.5334 & 186.3907 \\
\hline $0-7$ & 0.4599 & 41.2868 & 119.2653 & 9.5686 & 194.5886 \\
\hline $0-8$ & 0.4889 & 37.9254 & 114.5048 & 9.5139 & 180.0520 \\
\hline $0-9$ & 0.4680 & 30.7657 & 93.7720 & 9.4876 & 137.8641 \\
\hline $5-6$ & 0.5656 & 35.1384 & 79.5117 & 4.9491 & 137.3248 \\
\hline $5-7$ & 0.5505 & 34.5624 & 90.2150 & 9.6484 & 139.7103 \\
\hline $5-8$ & 0.5676 & 28.0184 & 93.1630 & 8.1383 & 135.3549 \\
\hline $5-9$ & 0.5403 & 26.0924 & 94.5474 & 11.5862 & 123.6040 \\
\hline
\end{tabular}

The set of data from these tables and advisement of substantive properties have led to the construction of models with parametric uncertainty. The lower bound of time constant $T$ in model (5) has been moved down to 5 $\mathrm{s}$ because of fast initial dynamics which should also be taken into consideration. Although the intended working point corresponds to reference values of $y 3$ at 4 and $5 \mathrm{~V}$, the models are going to cover all measured temperature areas:

$$
\begin{gathered}
G(s, K, T)=\frac{[0.2 ; 0.7]}{[5 ; 50] s+1} \\
G\left(s, K, \tau, T_{1}, T_{2}\right)=\frac{[0.2 ; 0.7]([25 ; 130] s+1)}{([3 ; 14] s+1)([70 ; 210] s+1)}
\end{gathered}
$$

\section{ALGEBRAIC SYNTHESIS}

The fractional approach developed by Vidyasagar (1985) and Kučera (1993) and discussed in (Prokop and Corriou 1997; Prokop et al. 2002) supposes that transfer functions of continuous-time linear causal systems in $\mathrm{R}_{\mathrm{PS}}$ are expressed as:

$$
G(s)=\frac{b(s)}{a(s)}=\frac{b(s)(s+m)^{-n}}{a(s)(s+m)^{-n}}=\frac{B(s)}{A(s)}
$$

where $n=\max \{\operatorname{deg}(a), \operatorname{deg}(b)\}$ and $m>0$.

Consider a two-degree-of-freedom (2DOF) control system from fig. 6. Take notice that the traditional one-degree-offreedom (1DOF) system is obtained simply by $R=Q$. 


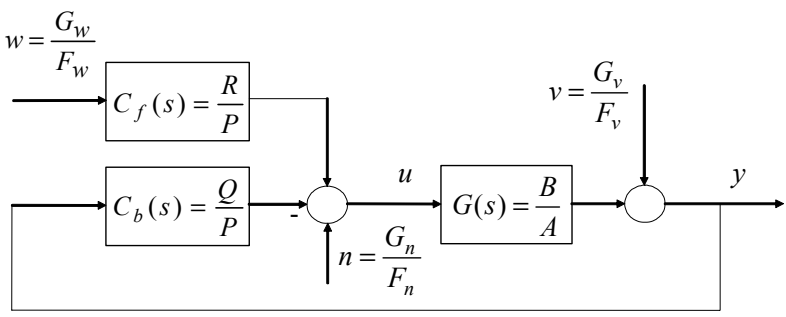

Figure 6: Two-Degree-of-Freedom Control System

External signals $w=\frac{G_{w}}{F_{w}}, \quad n=\frac{G_{n}}{F_{n}} \quad$ and $\quad v=\frac{G_{v}}{F_{v}}$ represent the reference, load disturbance and disturbance signal, respectively. The most frequent case is a stepwise for reference and load disturbance signal and a harmonic signal for disturbance. Denominators of their transfer functions are then $F_{w}=F_{n}=\frac{s}{s+m}$ and $F_{v}=\frac{s^{2}+\omega^{2}}{(s+m)^{2}}$, respectively.

Basic relations following from fig. 6 are:

$$
y=\frac{B}{A} u+v ; \quad u=\frac{R}{P} w-\frac{Q}{P} y+n
$$

Further, the following equations hold:

$$
y=\frac{B R}{A P+B Q} \frac{G_{w}}{F_{w}}+\frac{B P}{A P+B Q} \frac{G_{n}}{F_{n}}+\frac{A P}{A P+B Q} \frac{G_{v}}{F_{v}}
$$

Provided that no disturbances affect the control system, i.e. $n=v=0$, the control error is given by:

$$
e=w-y=\left(1-\frac{B R}{A P+B Q}\right) \frac{G_{w}}{F_{w}}
$$

For the structure 1DOF $(R=Q)$, the last relation takes the form:

$$
e=\frac{A P}{A P+B Q} \frac{G_{w}}{F_{w}}
$$

The basic task is to ensure stability of the system in fig. 6. All stabilizing feedback controllers are given by all solutions of the linear Diophantine equation:

$$
A P+B Q=1
$$

with a general solution $P=P_{0}+B T, Q=Q_{0}-A T$, where $T$ is free in $\mathrm{R}_{\mathrm{PS}}$ and $P_{0}, Q_{0}$ is a pair of particular solutions (Youla - Kučera parameterization of all stabilizing controllers). Details and proofs can be found e.g. in (Prokop and Corriou 1997; Prokop et al. 2002). Then relations (10) and (11) take the form:

$$
\begin{gathered}
e=(1-B R) \frac{G_{w}}{F_{w}} \\
e=A P \frac{G_{w}}{F_{w}}
\end{gathered}
$$

For asymptotic tracking then follows:

$F_{w}$ must divide $A P$ for $1 \mathrm{DOF}$

$F_{w}$ must divide $(1-B R)$ for $2 \mathrm{DOF}$

The last condition gives the second Diophantine equation for $2 \mathrm{DOF}$ structure:

$$
F_{w} S+B R=1
$$

The design process is demonstrated for first order system. A nominal transfer function is supposed as:

$$
G(s)=\frac{b_{0}}{s+a_{0}}
$$

Further, step-wise reference with $F_{w}=\frac{s}{s+m}$ and no disturbances are assumed. The Diophantine equation (12) takes the form:

$$
\frac{s+a_{0}}{s+m} p_{0}+\frac{b_{0}}{s+m} q_{0}=1
$$

Multiplying by $(s+m)$ and comparing coefficients give the general stabilizing solution in the form:

$$
P(s)=p_{0}+\frac{b_{0}}{s+m} T ; \quad Q(s)=q_{0}-\frac{s+a_{0}}{s+m} T
$$

where $q_{0}=\frac{m-a_{0}}{b_{0}} ; p_{0}=1$ and $T$ is free in $\mathrm{R}_{\mathrm{PS}}$. The asymptotic tracking for a stepwise reference $w$ is given by divisibility of $F_{w}=\frac{s}{s+m}$ and $A P$ (or only $P$ in this case). It is achieved for $T=t_{0}=-\frac{m}{b_{0}}$ so that $P$ has zero absolute coefficient in the numerator. Then inserting $t_{0}$ into (18) gives:

$$
\begin{gathered}
P(s)=\frac{s}{s+m} ; \quad Q(s)=\frac{\tilde{q}_{1} s+\tilde{q}_{0}}{s+m} \\
\tilde{q}_{1}=\frac{2 m-a_{0}}{b_{0}} ; \quad \tilde{q}_{0}=\frac{m^{2}}{b_{0}}
\end{gathered}
$$

Finally, the 1DOF controller has the transfer function:

$$
\frac{Q(s)}{P(s)}=\frac{\tilde{q}_{1} s+\tilde{q}_{0}}{s}
$$

Note that $\tilde{q}_{1}, \tilde{q}_{0}$ depend on single tuning parameter $m>0$. Hence, another topic of interest should be an appropriate choice of $m$. A potential way of nominal tuning can be found e.g. in (Matušů and Prokop 2008).

\section{CONTROL EXPERIMENTS}

First, the uncertain model (5) and nominal system (for controller design):

$$
G_{N}(s)=\frac{0.5}{25 s+1}=\frac{0.02}{s+0.04}
$$


have been assumed. The tuning parameter $m=0.0748$, which corresponds to $2 \%$ of first overshoot from (Matušů and Prokop 2008), has been selected. The computed 1DOF PI controller (21), (20) is:

$$
C_{b}(s)=\frac{\tilde{q}_{1} s+\tilde{q}_{0}}{s}=\frac{5.48 s+0.2798}{s}
$$

The characteristic polynomial of closed loop with plant (5) and controller (23) can be easily computed:

$$
\begin{aligned}
& p(s, K, T)=T s^{2}+\left(1+K \tilde{q}_{1}\right) s+K \tilde{q}_{0}= \\
& =[5 ; 50] s^{2}+[2.096 ; 4.836] s+[0.05596 ; 0.1959]
\end{aligned}
$$

This simple polynomial is obviously robustly stable, because it is of second order and all its coefficients are possitive, i.e. the whole system is robustly stable. The real closed-loop control behaviour can be seen in fig. 7 . The control signal is depicted only in $25 \%$ of its true size because of better perspicuity of controlled variable.

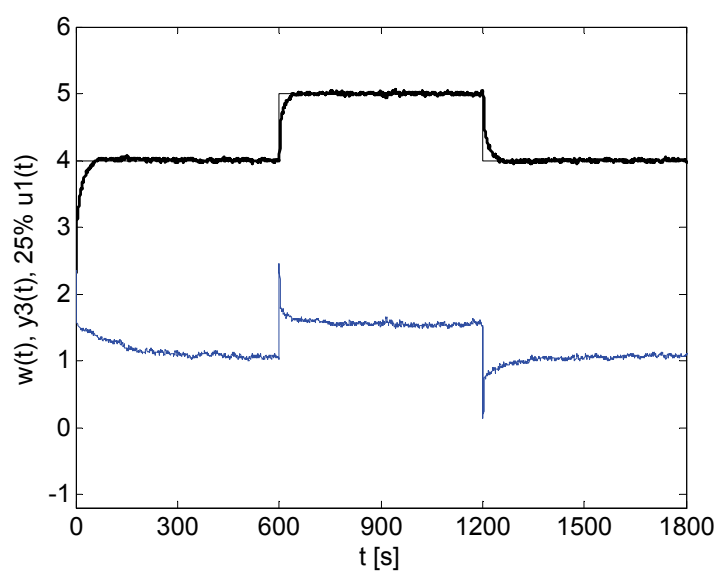

Figure 7: Control of Bulb Temperature by (23)

Next, it has been supposed the system with parametric uncertainty (6) and nominal plant:

$$
G_{N}(s)=\frac{0.5(100 s+1)}{(9 s+1)(150 s+1)}=\frac{0 . \overline{037} s+0.00 \overline{037}}{s^{2}+0.11 \overline{7} s+0.00 \overline{074}}
$$

Unfortunately, the single tuning parameter entails restraint for control design here and it is not easy to find suitable $m$ with "quality" control response. Using synthesis technique from previous section, the chosen value $m=0.025$ leads to $1 \mathrm{DOF}$ PID regulator:

$$
\begin{aligned}
& C_{b}(s)=\frac{\tilde{q}_{2} s^{2}+\tilde{q}_{1} s+\tilde{q}_{0}}{s^{2}+\tilde{p}_{1} s}= \\
& =\frac{-1.1556 s^{2}+0.01324 s+0.001055}{s^{2}+0.02502 s}
\end{aligned}
$$

The plant (6) and controller (26) leads to closed-loop characteristic polynomial:

$$
\begin{aligned}
& p\left(s, K, \tau, T_{1}, T_{2}\right)=T_{1} T_{2}\left(s^{4}+\tilde{p}_{1} s^{3}\right)+ \\
& +\left(T_{1}+T_{2}\right)\left(s^{3}+\tilde{p}_{1} s^{2}\right)+K \tau\left(\tilde{q}_{2} s^{3}+\tilde{q}_{1} s^{2}+\tilde{q}_{0} s\right)+ \\
& +K\left(\tilde{q}_{2} s^{2}+\tilde{q}_{1} s+\tilde{q}_{0}\right)+\left(s^{2}+\tilde{p}_{1} s\right)
\end{aligned}
$$

The value sets of this family with multilinear uncertainty structure, plotted via the Polynomial Toolbox for Matlab (Polyx; Šebek et al. 2000) for several non-negative frequencies, are depicted in fig. 8. Unluckily, the zero exclusion condition indicates that polynomial (27) and thus also the whole control system is not robustly stable for assumed range of uncertain parameters, because the value sets include the zero point. The boundaries in (6) are too broad (the requirements are too strong). Margins have to be narrowed to gain the closed loop robustly stable with the controller (26). For details about this very universal and effective technique for graphical testing of robust stability and related topics see e.g. (Barmish 1994; Bhattacharyya et al. 1995). However, the real system has been stable in used working point (with nonminimum phase behaviour), as can be seen in fig. 9 .

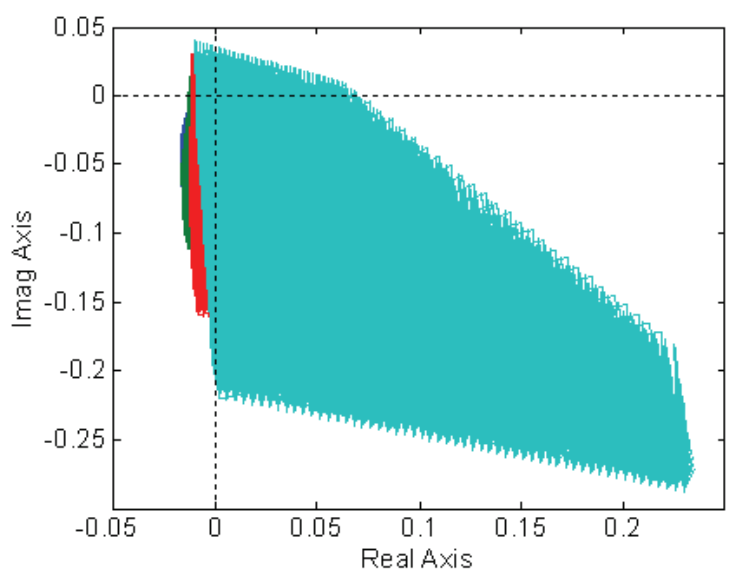

Figure 8: Value Sets for (27) with Parameters (26)

If $2 \mathrm{DOF}$ structure and $m=0.02$ is used, the final controller arises in the form:

$$
\begin{aligned}
& C_{b}(s)=\frac{-1.3701 s^{2}+0.01727 s+0.000432}{s^{2}+0.01297 s} \\
& C_{f}(s)=\frac{1.08 s^{2}+0.0432 s+0.000432}{s^{2}+0.01297 s}
\end{aligned}
$$

The feedforward part does not influence robust stability, i.e. this controller would ensure it under similar conditions as in the previous case. The fig. 10 presents the control results.

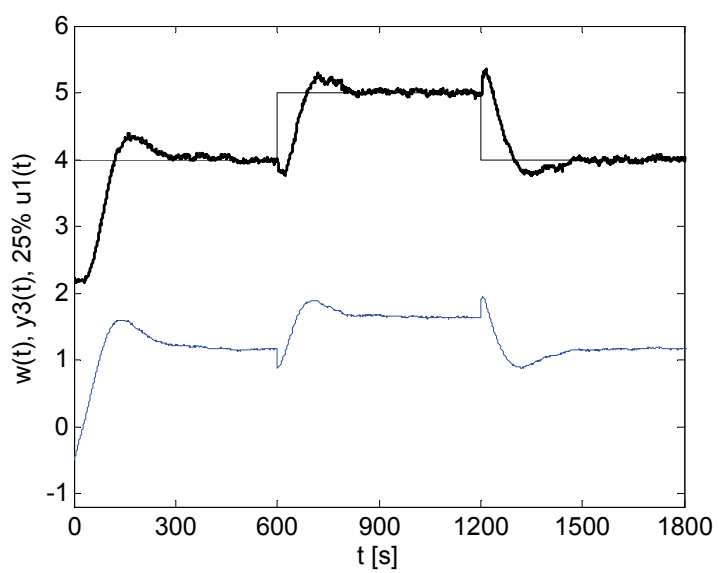

Figure 9: Control of Bulb Temperature by (26) 


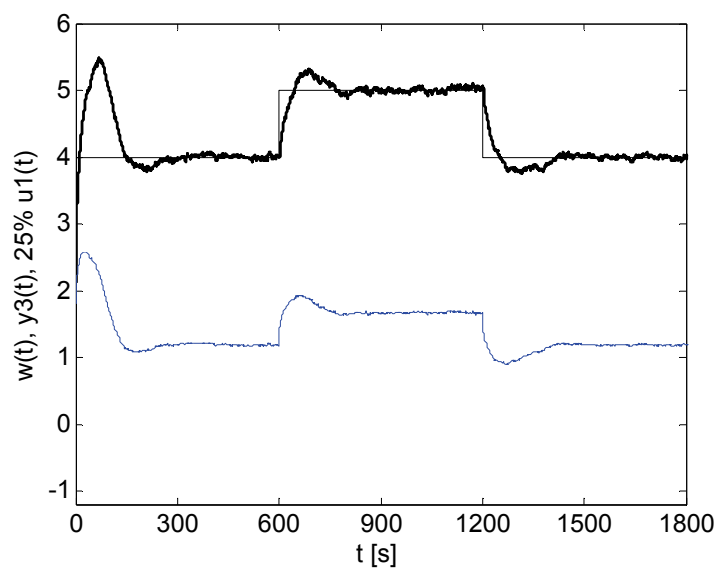

Figure 10: Control of Bulb Temperature by (28)

Another possibility of simplifying (instead of approximation by first order model) can be done via additional order reduction in identified second order system. The order reductions first only in numerator and afterward both in numerator and denominator lead to nominal transfer functions, respectively:

$$
\begin{gathered}
G_{N}(s)=\frac{0.00 \overline{037}}{s^{2}+0.11 \overline{7} s+0.00 \overline{074}}= \\
=\frac{0.5}{(9 s+1)(150 s+1)} \approx \frac{0.5(100 s+1)}{(9 s+1)(150 s+1)} \\
G_{N}(s)=\frac{0.003145}{s+0.006289}=\frac{0.5}{159 s+1} \approx \frac{0.5(100 s+1)}{(9 s+1)(150 s+1)}
\end{gathered}
$$

The former approximation (29) and $m=0.04$ result in:

$$
C_{b}(s)=\frac{10.4933 s^{2}+0.6068 s+0.006912}{s^{2}+0.04222 s}
$$

while the latter one (30) and $m=0.0204$ (6\% first overshoot for nominal system) lead to the controller:

$$
C_{b}(s)=\frac{10.9733 s+0.1323}{s}
$$

The plant (6) and the controller (31) give, again, the closed-loop characteristic polynomial with structure (27).

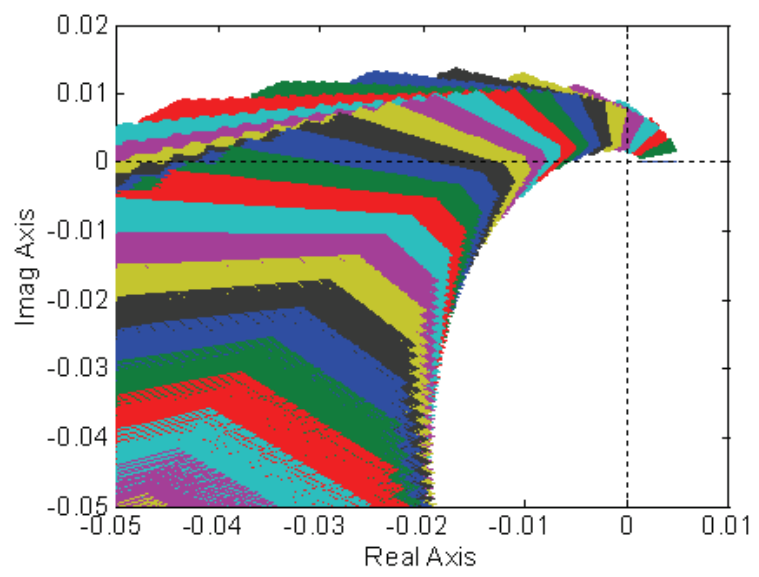

Figure 11: Value Sets for (27) with Parameters (31)
Nevertheless, in this instance, the closed-loop polynomial (27) is robustly stable which results from the fact that the origin of the complex plane is not included in the value sets (see Fig. 11) and (27) has a stable member (Barmish 1994). Thus the whole control system is robustly stable.

Furthermore, the controlled system (6) and the regulator (32) yield the polynomial:

$$
\begin{aligned}
& p\left(s, K, \tau, T_{1}, T_{2}\right)=T_{1} T_{2} s^{3}+\left(T_{1}+T_{2}\right) s^{2}+ \\
& +K \tau\left(\tilde{q}_{1} s^{2}+\tilde{q}_{0} s\right)+K\left(\tilde{q}_{1} s+\tilde{q}_{0}\right)+s
\end{aligned}
$$

which is also robustly stable as follows from Fig. 12. The figs. 13 and 14 show the control responses for both cases.

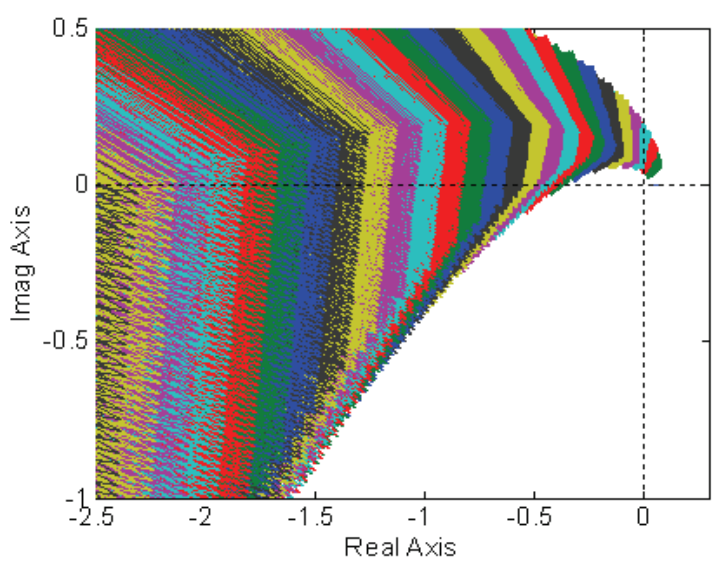

Figure 12: Value Sets for (33) with Parameters (32)

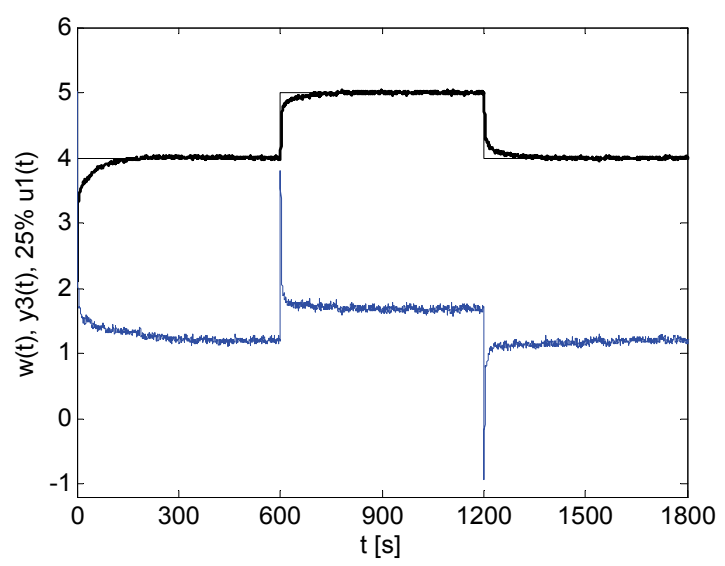

Figure 13: Control of Bulb Temperature by (31)

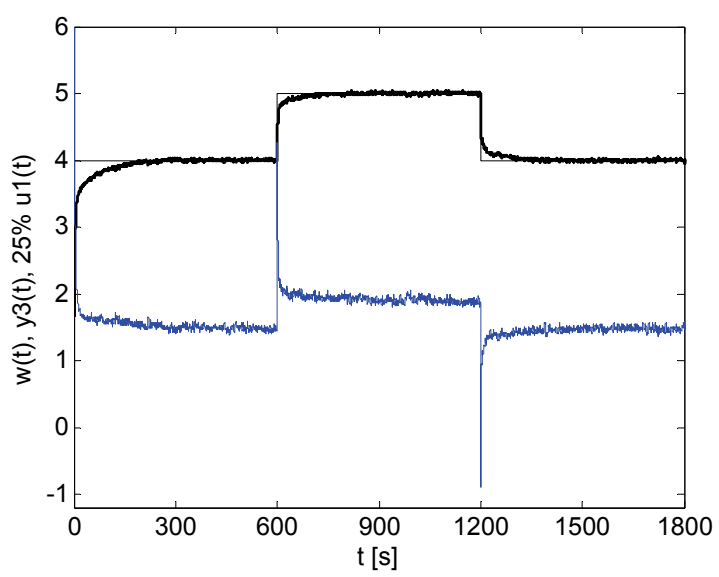

Figure 14: Control of Bulb Temperature by (32) 


\section{EVALUATION AND CONCLUSION}

The objective evaluation of quality has been performed by meaning of Integrated Squared Error (ISE) criterion. The quantification is expressed in table 4 .

Table 4: Outcomes of ISE Calculations

\begin{tabular}{|c|c|}
\hline Controller & ISE \\
\hline$(23)$ & 19.2579 \\
\hline$(26)$ & 370.7898 \\
\hline$(28)$ & 166.0868 \\
\hline$(31)$ & 18.8931 \\
\hline$(32)$ & 28.4738 \\
\hline
\end{tabular}

The controllers (31) and (23) achieve the best ISE results. However, the regulator (23) generates "less aggressive" actuating signal after step-changes of reference. On the contrary, controller (26) is the worst, moreover with non-minimum phase behaviour. Not an application of 2DOF structure (28) brings about considerable improvement. Problems in control, which paradoxically emerge during use of identified second order model (6) and nominal system (25) are caused by synthesis limitation using single tuning parameter. It arises here as the cost for tuning simplicity.

\section{ACKNOWLEDGEMENT}

The work was supported by the Ministry of Education, Youth and Sports of the Czech Republic under Research Plan No. MSM 7088352102. This assistance is very gratefully acknowledged.

\section{REFERENCES}

Barmish, B.R. 1994. New Tools for Robustness of Linear Systems. Macmillan, New York, USA.

Bhattacharyya, S.P.; H. Chapellat and L.H. Keel. 1995. Robust Control: The Parametric Approach. Prentice Hall, Englewood Cliffs, New Jersey, USA.

Dušek, F. and D. Honc. 2002. "Utilization of serial link under MATLAB 6 (Využití sériové linky pod MATLABem verze 6)". In Proceedings of conference MATLAB 2002 (Prague, Czech Republic). (In Czech).

Klán, P.; D. Honc and J. Jindřich. 2003. "New measuring unit CTRL V3 (Nová měřicí jednotka CTRL V3)”. In Proceedings of conference MATLAB 2003 (Prague, Czech Republic). (In Czech).

Kučera, V. 1993. "Diophantine equations in control - A survey”. Automatica, Vol. 29, No. 6, 1361-1375.

Matušů, R. and R. Prokop. 2008. "Single-Parameter Tuning of PI Controllers: From Theory to Practice". In Proceedings of the 17th IFAC World Congress (Seoul, Korea).

Matušů, R.; R. Prokop and M. Dlapa. 2008. "Robust Control of Temperature in Hot-Air Tunnel". In Proceedings of the 16th Mediterranean Conference on Control and Automation (Ajaccio, France).
Polyx. "The Polynomial Toolbox". [online]. [cit. 01-02-2010]. Available from URL: <http://www.polyx.com/>.

Prokop, R. and J.P. Corriou. 1997. "Design and analysis of simple robust controllers". International Journal of Control, Vol. 66, No. 6, 905-921.

Prokop, R.; P. Husták and Z. Prokopová. 2002. "Simple robust controllers: Design, tuning and analysis". In Proceedings of the 15th IFAC World Congress (Barcelona, Spain).

Šebek, M.; M. Hromčík and J. Ježek. 2000. "Polynomial toolbox 2.5 and systems with parametric uncertainties". In Proceedings of the 3rd IFAC Symposium on Robust Control Design (Prague, Czech Republic).

Smutný, L.; J. Škuta and J. Farník. 2002. "Model of hot-air circuit (Model teplovzdušného obvodu)". Technical report to HS 311107 "Technická pomoc při návrhu a zhotovení modelu teplovzdušného obvodu", VŠB-TU Ostrava, Czech Republic. (In Czech).

Vidyasagar, M. 1985. Control System Synthesis: A Factorization Approach. MIT Press, Cambridge, MA, USA.

\section{AUTHOR BIOGRAPHIES}

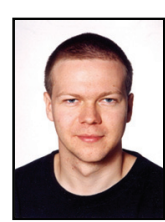

RADEK MATUŠŮ was born in Zlín, Czech Republic in 1978. He is a Researcher at Faculty of Applied Informatics of Tomas Bata University in Zlín. He graduated from Faculty of Technology of the same university with an MSc in Automation and Control Engineering in 2002 and he received a PhD in Technical Cybernetics from Faculty of Applied Informatics in 2007. He worked as a Lecturer from 2004 to 2006. The main fields of his professional interest include robust systems and application of algebraic methods to control design. His e-mail address is: rmatusu@fai.utb.cz and his web-page can be found at: http://zamestnanci.fai.utb.cz/ matusu/.

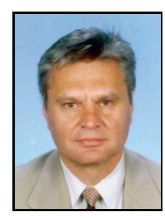

ROMAN PROKOP was born in Hodonín, Czech Republic in 1952. He graduated in Cybernetics from the Czech Technical University in Prague in 1976. He received post graduate diploma in 1983 from the Slovak Technical University. Since 1995 he has been at Tomas Bata University in Zlín, where he presently holds the position of full professor of the Department of Automation and Control Engineering and a vice-dean of the Faculty of Applied Informatics. His research activities include algebraic methods in control theory, robust and adaptive control, autotuning and optimization techniques. His e-mail address is: prokop@fai.utb.cz. 